\title{
Aplicação de modelos matemáticos na estimativa do volume de bulbo molhado por gotejamento superficial em diferentes tipos de solo
}

\author{
Application of mathematical models to estimate the wet soil volume in superficial drip irrigation \\ in different types of soils
}

\author{
Celsemy Eleutério Maia ${ }^{I^{*}}$
}

\section{RESUMO}

\begin{abstract}
A informação do volume de solo molhado pela irrigação localizada é importante para o dimensionamento e manejo da irrigação por gotejamento superficial, bem como para a estimativa da quantidade de água disponivel para as plantas. Com o objetivo de avaliar cinco modelos para estimar o volume molhado pela irrigação por gotejamento superficial, foram instalados experimentos em seis tipos de solos (Luvissolo Crômico, Argissolo Vermelho-Amarelo, Cambissolo Háplico, Neossolo Quartzarênico, Latossolo Vermelho e Neossolo Flúvico). A partir desses experimentos, constatou-se que, com exceção do modelo proposto por NARDA \& CHAWLA, os demais modelos estimam satisfatoriamente o volume de solo molhado pela irrigação por gotejamento superficial. Além disso, concluiu-se que o volume médio molhado para as mesmas combinações entre a vazão do emissor e o tempo de aplicação de água foram maiores para o Argissolo e menores para o Neossolo Flúvico e que, com exceção do Argissolo e do Neossolo Flúvico, o volume molhado do solo pode ser estimado por uma única equação em função do volume de água aplicado $e$ do tempo de aplicação de água.
\end{abstract}

Palavras-chave: modelagem da água e no solo, infiltração de água no solo, projeto de irrigação.

\section{ABSTRACT}

The information of wetting soil volume under drip irrigation has great importance in design and management of surface drip irrigation for delivering required amount of water to the plant. This study aimed to describe the wetted soil volume for five mathematic models by water applied on soil surface from drip emitter. For that, six experiments were installed in different soils (Entisol, Ultisol, Inceptisol, Psamment, Oxisol, Fluvent) with the objective of evaluating models which can estimate wetted soil volume in function of emitter discharged and time of water application. It was concluded that except for the model proposed by NARDA \& CHAWLA, the other models estimated satisfactorily the wetted soil volume for the superficial drip irrigation. The wetted soil volume for the same combinations of emitter discharged and water application time, were larger for Ultisol and smaller for Fluvent and excepting Ultisol and Fluvent, the wetted soil volume can be estimated for a single equation in function of emitter discharged and time of water application.

Key words: water and soil modeling, soil water infiltration, irrigation management.

\section{INTRODUÇÃO}

O conhecimento das dimensões do bulbo molhado tem importância para a determinação da profundidade e da largura máximas no planejamento da irrigação, evitando assim perdas de água por lixiviação e superposição exagerada dos emissores. Do ponto de vista agronômico, as dimensões do bulbo são úteis para se determinar o volume de solo molhado pela irrigação localizada, onde encontram-se concentradas as raízes das plantas. Além disso, o conhecimento dessas dimensões também é útil nos cálculos da lâmina de água a aplicar e da quantidade de nutriente no volume molhado, sendo fundamental para o programa da fertirrigação.

Estudos que mostram o comportamento do bulbo molhado em função do tipo de solo, da vazão do emissor e do tempo de aplicação de água podem ser

'Departamento de Ciências Ambientais e Tecnológicas, Universidade Federal Rural do Semiárido (UFERSA), 59625-900, Mossoró, RN, Brasil. E-mail: celsemy@ufersa.edu.br. "Autor para correspondência. 
usados para estimar o espaçamento entre os emissores. Trabalhos como o de BRESLER (1978) mostram que, em solos com condutividade hidráulica saturada $\left(K_{s}\right)$ e $\alpha$ (coeficiente do solo) pequeno, o espaçamento entre os emissores é maior, como também ocorre em culturas pouco sensíveis ao estresse de água. Já em solos com $K_{s}$ e $\alpha$ maiores, o espaçamento entre os emissores é menor. Isso implica que o espaçamento entre os emissores pode ser aumentado com o aumento da vazão do emissor. Isso é mostrado claramente no trabalho de BRESLER (1978), onde se observa que, com o aumento da vazão do emissor e um decréscimo em $K_{s}$, tem-se o aumento do raio superficial molhado.

Nesse sentido, o volume de solo molhado por um único emissor é importante para o dimensionamento da irrigação localizada, determinando-se assim o número total de emissores necessários para molhar parte do solo, a fim de se aplicar água de acordo com a necessidade hídrica das plantas, o que se dá em função da textura do solo, da estrutura, da taxa de aplicação (vazão do emissor) e do volume de água aplicado (relacionado com o tempo de irrigação). Segundo LUBANA \& NARDA (1998), a forma e o volume molhado do solo variam principalmente conforme suas características hidráulicas, o número de emissores, a vazão dos emissores e a frequência de irrigação, que precisam ser determinados para que o volume molhado seja suficiente para que as plantas supram suas necessidades hídricas. Outros fatores, como propriedades físicas do solo, umidade inicial do solo (SANTOS et al., 2003) e lâmina de irrigação (SIMONNE et al., 2005), afetam o volume de solo molhado na irrigação localizada por gotejamento. Poucos trabalhos estudam o volume do bulbo molhado, sendo que, na maioria das vezes, estuda-se apenas as dimensões do bulbo em relação ao tempo de aplicação de água e à vazão do emissor, como observado em MAIA et al. (2010) e THABET \& ZAYANI (2008). Outros autores estudaram as dimensões do bulbo no solo em função da quantidade de água aplicada, tais como HAO et al. (2007) e BARRETO et al. (2008), porém poucos trabalhos avaliaram o volume de solo molhado, destacando-se, entre esses, PROVENZANO (2007), SINGH et al. (2006) e FARNESELLI et al. (2008).

O objetivo deste trabalho foi avaliar quatro modelos para determinação do volume do bulbo molhado na irrigação localizada por gotejamento superficial em seis solos do Estado do Rio Grande do Norte.

\section{MATERIAL E MÉTODOS}

O trabalho foi realizado em um região caracterizada, segundo a classificação de Köppen, como BSwh', apresentando temperatura média anual de $27,4^{\circ} \mathrm{C}$, precipitação pluviométrica anual bastante irregular, com média de $673,9 \mathrm{~mm}$, e umidade relativa de 68,9\% (CARMO FILHO et al., 1991).

Para o estudo, foram selecionados seis tipos diferentes de solos, sendo classificados, segundo EMBRAPA (2006), como Luvissolo Crômico, Argissolo Vermelho-Amarelo, Cambissolo Háplico, Neossolo Quartizarênico, Latossolo Vermelho e Neossolo Flúvico. Antes da montagem do sistema de irrigação, os solos foram preparados de forma similar para simular as reais condições de plantio, com aração e passagem da grade de disco de forma cruzada.

Para se determinar com maior exatidão o tamanho do bulbo molhado (diâmetro da área molhada e profundidade), desenvolveu-se um sistema de irrigação portátil, onde foram dispostos oito emissores por linha, distribuídos aleatoriamente na parcela, ao longo de uma tubulação de polietileno de $16 \mathrm{~mm}$ de diâmetro, abastecida por dois depósitos de água, sendo um de $1000 \mathrm{~L}$ e outro de 500L. Para regular a vazão e a pressão, foram utilizados reservatórios reguladores, conectados aos primeiros, que mantinham um nível constante por um sistema de boia, sendo sua haste alterada de forma que sua carga hidráulica se mantivesse estável.

Os experimentos foram instalados em delineamento em blocos inteiramente casualizados, em parcela subdividida, com três repetições, cujos tratamentos foram compostos pelos fatores tempo de aplicação de água e vazão do emissor, sendo a parcela o tempo e a subparcela a vazão do emissor,. As repetições constaram de duas linhas de irrigação com quatro diferentes tempos (1, 2, 4 e 7h) e, dentro de cada tempo, as vazões de $1,2,4$ e $8 \mathrm{~L} \mathrm{~h}^{-1}$ obtidas por microtubos de tamanhos diferenciados, que proporcionam as vazões desejadas sob as mesmas condições de carga hidráulica. $\mathrm{O}$ espaçamento entre os emissores foi de tal modo que não houvesse sobreposição dos bulbos.

Para cada vazão, imediatamente após os tempos pré-determinados de 1, 2, 4 e 7h, foram abertas trincheiras no centro do bulbo molhado, abaixo do emissor, onde foram realizadas as medições das dimensões do bulbo com fita métrica com precisão de $1,0 \mathrm{~mm}$. Para avaliar o efeito da vazão do emissor e do tempo de aplicação de água na formação do bulbo molhado, avaliaram-se as seguintes características: diâmetro superficial $\left(D_{s}\right)$, diâmetro máximo $\left(D_{\max }\right)$, profundidade máxima $\left(Z_{\max }\right)$ e profundidade, onde se verificou $D_{\max }\left(Z_{D \max }\right)$.

O volume do bulbo molhado foi estimado por quatro metodologias: pelo volume da elipse 
truncada (ZUR, 1996) (Equação 1), pela revolução do modelo quadrático (RMQ), equações 2 e 3 , pelo modelo proposto por NARDA \& CHAWLA (2002) (NC), equações 4 e 5 , e pela correção do volume do cilindro (CVC), conforme as equações 6 e 7.

$V=\frac{\pi}{12} D_{\max }^{2}\left[2 Z_{\text {max }}+Z_{D \text { max }}-\frac{Z_{D \text { max }}^{3}}{\left(Z_{\text {max }}-Z_{D \text { max }}\right)^{2}}\right]$

Para o modelo quadrático, sendo $D(\mathrm{z})=$ $a+b \mathrm{Z}+c \mathrm{Z}^{2}$, o volume do bulbo molhado pode ser estimado pela revolução do modelo quadrático, de acordo com as equações 2 e 3 :

$V=\frac{\pi}{4} \int_{0}^{Z \max }[D(Z)]^{2} d z$

ou

$V=\frac{\pi}{4}\left(a^{2} Z+a b Z^{2}+\frac{2 a c Z^{3}}{3}+\frac{b^{2} Z^{3}}{3}+\frac{b c Z^{4}}{2}+\frac{c^{2} Z^{5}}{5}\right)$

Segundo NARDA \& CHAWLA (2002), o volume da forma elipsoidal é obtido pela equação 4 ou pela 5:

$V=\frac{4}{3} \pi r^{2} z$

Substituindo-se o raio pelo diâmetro, tem-se

$V=\frac{\pi}{3} D^{2} \cdot z$

Nessa equação, tem-se o bulbo molhado circunscrito em um cilindro de área superficial e de altura iguais a $\frac{\pi \cdot D_{\max }^{2}}{4} \mathrm{e} Z_{\max }$, respectivamente, sendo o volume do cilindro igual a $V_{c}=\frac{\pi \cdot D_{\max }^{2}}{4} Z_{\max }$, em que o volume do bulbo molhado é obtido fazendo-se a correção por meio de um fator $\left(f_{c}\right)$ dado pela equação 6 :

$f_{c}=\left[\left(\frac{D_{s}}{D_{\max }}\right)^{1 / 6} \cdot 6\right]^{1 / 6}$

Assim, o volume do bulbo molhado pode ser determinado pela equação 7 :

$V=\frac{\pi \cdot D_{\max }^{2}}{4} \frac{Z_{\max }}{f_{c}}$

Para avaliar o volume do bulbo molhado em função do volume de água aplicado, fez-se o teste de identidade de modelo de acordo com REGAZZI (1999), a fim de se saber se uma única equação poderia ser utilizada para os diferentes solos estudados. Avaliouse ainda o volume do bulbo molhado por cada modelo em função do tempo de aplicação de água $(t)$ e da vazão do emissor $(q)$, usando-se, para isso, o modelo de superfície de resposta $V=a \cdot t^{b} \cdot q^{c}$.

\section{RESULTADOS E DISCUSSÃO}

Considerando-se o volume do bulbo obtido pela metodologia proposta por ZUR (1996), utilizada como referência por ter um embasamento teórico sobre o volume molhado no solo (elipse truncada), observouse que os volumes dos bulbos obtidos para cada solo em função da vazão do emissor e do tempo de aplicação de água foram semelhantes, diferindo apenas para o modelo proposto por NARDA \& CHAWLA(2002), que superestimou o volume do bulbo em aproximadamente o dobro, conforme se vê nas tabelas 1 e 2 . Isso se deve ao fato de a equação utilizada por esses autores para o cálculo do volume apresentar um equívoco. Sendo a equação sugerida por NARDA \& CHAWLA (2002)

igual a $V=\frac{4}{3} \pi r^{2} z \quad$ (possivelmente com base no volume da esfera, que é dado por $V_{e}=\frac{4}{3} \pi r^{3}$ )

e, considerando-se um bulbo molhado circunscrito em um cilindro, seu volume $\left(V_{b}\right)$ necessariamente tem que ser menor que o do cilindro $\left(V_{c}\right)$, cujo volume é dado por $V_{c}=\pi D_{\max }^{2} \cdot Z_{\max }$.

Analisando-se o modelo sugerido por NARDA \& CHAWLA (2002) e fazendo-se a

substituição do raio por $D_{\max / 2}$, tem-se $V_{b}=\frac{\pi}{3} D_{\max }^{2} \cdot Z_{\max }$, como $V_{c}=\pi D_{\max }^{2} \cdot Z_{\max }$, tem-se $V_{b}=\frac{4}{3} V_{c}$. Como a relação

4/3 é maior que 1 , o volume do bulbo molhado proposto por NARDA \& CHAWLA (2002) é superior ao volume do cilindro em que o bulbo está circunscrito, o que não é correto. A correção necessária é inverter 4/3 para 3/4.

Assim, $V=\frac{3}{4} \pi r^{2} z$ será chamado de M100 nas tabelas

1 e 2, onde se observa boa relação com o volume obtido pela metodologia proposta por ZUR (1996).

A relação entre o volume do bulbo molhado estimado pelos modelos e comparado com o de ZUR (1996), que é tido como referência, pode ser observado na figura 1. Para a comparação de modelos, deseja-se que o coeficiente angular e o intercepto da reta sejam estatisticamente iguais a de 1 e 0 , respectivamente. Nesse sentido, verificou-se que, com exceção do modelo proposto por NARDA \& CHAWLA (2002), os modelos da revolução do modelo quadrático (RMQ), 
Tabela 1 - Volume do bulbo molhado $\left(\mathrm{m}^{3}\right)$ estimado pelo modelo proposto por ZUR (1996), Narda \& Chawla (2002) (NC), pela revolução do modelo quadrático(RMQ), pela correção do volume do cilindro (CVC) e baseado no volume da esfera (M100), em função do tempo de aplicação de água (h) e da vazão do emissor $\left(\mathrm{L} \mathrm{h}^{-1}\right)$, para o Luvissolo Crômico, o Argissolo Vermelho-Amarelo e o Cambissolo Háplico.

\begin{tabular}{|c|c|c|c|c|c|c|c|}
\hline Solo & Tempo & Vazão & ZUR & $\mathrm{NC}$ & RMQ & $\mathrm{CVC}$ & M100 \\
\hline \multirow{16}{*}{ Luvissolo Crômico } & 1 & 1 & 0,0053 & 0,0100 & 0,0055 & 0,0056 & 0,0056 \\
\hline & 1 & 2 & 0,0134 & 0,0241 & 0,0134 & 0,0135 & 0,0136 \\
\hline & 1 & 4 & 0,0232 & 0,0416 & 0,0263 & 0,0232 & 0,0234 \\
\hline & 1 & 8 & 0,0420 & 0,0754 & 0,0439 & 0,0420 & 0,0424 \\
\hline & 2 & 1 & 0,0116 & 0,0209 & 0,0108 & 0,0117 & 0,0118 \\
\hline & 2 & 2 & 0,0239 & 0,0425 & 0,0252 & 0,0238 & 0,0239 \\
\hline & 2 & 4 & 0,0504 & 0,0896 & 0,0506 & 0,0501 & 0,0504 \\
\hline & 2 & 8 & 0,0822 & 0,1474 & 0,0851 & 0,0825 & 0,0829 \\
\hline & 4 & 1 & 0,0207 & 0,0368 & 0,0205 & 0,0206 & 0,0207 \\
\hline & 4 & 2 & 0,0450 & 0,0800 & 0,0457 & 0,0447 & 0,0450 \\
\hline & 4 & 4 & 0,0849 & 0,1529 & 0,0891 & 0,0857 & 0,0860 \\
\hline & 4 & 8 & 0,1655 & 0,2992 & 0,1764 & 0,1676 & 0,1683 \\
\hline & 7 & 1 & 0,0312 & 0,0557 & 0,0341 & 0,0310 & 0,0313 \\
\hline & 7 & 2 & 0,0717 & 0,1293 & 0,0810 & 0,0723 & 0,0727 \\
\hline & 7 & 4 & 0,1909 & 0,3430 & 0,1874 & 0,1925 & 0,1929 \\
\hline & 7 & 8 & 0,3403 & 0,6071 & 0,3200 & 0,3406 & 0,3415 \\
\hline \multirow{16}{*}{$\begin{array}{l}\text { Argissolo Vermelho- } \\
\text { Amarelo }\end{array}$} & 1 & 1 & 0,0075 & 0,0136 & 0,0069 & 0,0076 & 0,0076 \\
\hline & 1 & 2 & 0,0119 & 0,0211 & 0,0126 & 0,0118 & 0,0119 \\
\hline & 1 & 4 & 0,0292 & 0,0520 & 0,0318 & 0,0290 & 0,0293 \\
\hline & 1 & 8 & 0,0482 & 0,0860 & 0,0473 & 0,0480 & 0,0484 \\
\hline & 2 & 1 & 0,0113 & 0,0203 & 0,0120 & 0,0113 & 0,0114 \\
\hline & 2 & 2 & 0,0268 & 0,0478 & 0,0281 & 0,0267 & 0,0269 \\
\hline & 2 & 4 & 0,0605 & 0,1076 & 0,0638 & 0,0601 & 0,0605 \\
\hline & 2 & 8 & 0,1093 & 0,1943 & 0,1098 & 0,1086 & 0,1093 \\
\hline & 4 & 1 & 0,0276 & 0,0491 & 0,0284 & 0,0274 & 0,0276 \\
\hline & 4 & 2 & 0,0524 & 0,0938 & 0,0550 & 0,0525 & 0,0527 \\
\hline & 4 & 4 & 0,1279 & 0,2324 & 0,1300 & 0,1306 & 0,1307 \\
\hline & 4 & 8 & 0,1997 & 0,3551 & 0,1949 & 0,1985 & 0,1998 \\
\hline & 7 & 1 & 0,0439 & 0,0783 & 0,0445 & 0,0438 & 0,0440 \\
\hline & 7 & 2 & 0,1011 & 0,1835 & 0,1075 & 0,1029 & 0,1032 \\
\hline & 7 & 4 & 0,2361 & 0,4372 & 0,2441 & 0,2461 & 0,2459 \\
\hline & 7 & 8 & 0,4676 & 0,8385 & 0,4183 & 0,4720 & 0,4717 \\
\hline \multirow{16}{*}{ Cambissolo Háplico } & 1 & 1 & 0,0046 & 0,0083 & 0,0045 & 0,0046 & 0,0046 \\
\hline & 1 & 2 & 0,0104 & 0,0200 & 0,0112 & 0,0111 & 0,0113 \\
\hline & 1 & 4 & 0,0220 & 0,0402 & 0,0213 & 0,0224 & 0,0226 \\
\hline & 1 & 8 & 0,0408 & 0,0754 & 0,0442 & 0,0420 & 0,0424 \\
\hline & 2 & 1 & 0,0096 & 0,0175 & 0,0089 & 0,0097 & 0,0098 \\
\hline & 2 & 2 & 0,0223 & 0,0404 & 0,0220 & 0,0225 & 0,0227 \\
\hline & 2 & 4 & 0,0465 & 0,0862 & 0,0479 & 0,0480 & 0,0485 \\
\hline & 2 & 8 & 0,1095 & 0,2007 & 0,1072 & 0,1118 & 0,1129 \\
\hline & 4 & 1 & 0,0174 & 0,0309 & 0,0183 & 0,0173 & 0,0174 \\
\hline & 4 & 2 & 0,0545 & 0,0976 & 0,0547 & 0,0544 & 0,0549 \\
\hline & 4 & 4 & 0,1127 & 0,2012 & 0,1187 & 0,1125 & 0,1132 \\
\hline & 4 & 8 & 0,2045 & 0,3657 & 0,1888 & 0,2042 & 0,2057 \\
\hline & 7 & 1 & 0,0397 & 0,0716 & 0,0370 & 0,0399 & 0,0402 \\
\hline & 7 & 2 & 0,1010 & 0,1808 & 0,1035 & 0,1008 & 0,1017 \\
\hline & 7 & 4 & 0,2162 & 0,3844 & 0,2178 & 0,2147 & 0,2162 \\
\hline & 7 & 8 & 0,3510 & 0,6378 & 0,3523 & 0,3584 & 0,3588 \\
\hline
\end{tabular}

Ciência Rural, v.40, n.11, nov, 2010. 
Tabela 2 - Volume do bulbo molhado $\left(\mathrm{m}^{3}\right)$ pelas metodologias propostas por ZUR (1996), Narda \& Chawla (2002) (NC), pela revolução do modelo quadrático (RMQ) e pela correção do volume do cilindro (CVC) e baseado no volume da esfera (M100), em função do tempo de aplicação de água (h) e da vazão do emissor $\left(\mathrm{L} \mathrm{h}^{-1}\right)$, para o Neossolo Qurtzarênico, o Latossolo Vermelho e o Neossolo Flúvico.

\begin{tabular}{|c|c|c|c|c|c|c|c|}
\hline Solo & Tempo (h) & $\begin{array}{l}\text { Vazão } \\
\left(\mathrm{L} \mathrm{h}^{-1}\right)\end{array}$ & Zur & $\mathrm{NC}$ & RMQ & $\mathrm{CVC}$ & M100 \\
\hline \multirow{17}{*}{ Neossolo Quartzarênico } & 1 & 1 & 0,0058 & 0,0107 & 0,0055 & 0,0059 & 0,0060 \\
\hline & 1 & 2 & 0,0132 & 0,0235 & 0,0130 & 0,0131 & 0,0132 \\
\hline & 1 & 4 & 0,0258 & 0,0474 & 0,0237 & 0,0264 & 0,0267 \\
\hline & 1 & 8 & 0,0462 & 0,0821 & 0,0440 & 0,0459 & 0,0462 \\
\hline & 2 & 1 & 0,0099 & 0,0180 & 0,0099 & 0,0100 & 0,0101 \\
\hline & 2 & 2 & 0,0242 & 0,0431 & 0,0237 & 0,0241 & 0,0242 \\
\hline & 2 & 4 & 0,0621 & 0,1103 & 0,0581 & 0,0618 & 0,0621 \\
\hline & 2 & 8 & 0,0768 & 0,1387 & 0,0880 & 0,0775 & 0,0780 \\
\hline & 4 & 1 & 0,0218 & 0,0388 & 0,0220 & 0,0216 & 0,0218 \\
\hline & 4 & 2 & 0,0519 & 0,0925 & 0,0463 & 0,0517 & 0,0520 \\
\hline & 4 & 4 & 0,1231 & 0,2216 & 0,1174 & 0,1245 & 0,1246 \\
\hline & 4 & 8 & 0,1929 & 0,3527 & 0,2093 & 0,1978 & 0,1984 \\
\hline & 7 & 1 & 0,0357 & 0,0635 & 0,0363 & 0,0355 & 0,0357 \\
\hline & 7 & 2 & 0,0835 & 0,1561 & 0,0953 & 0,0875 & 0,0878 \\
\hline & 7 & 4 & 0,2447 & 0,4573 & 0,2547 & 0,2576 & 0,2572 \\
\hline & 7 & 8 & 0,3367 & 0,6757 & 0,3923 & 0,3811 & 0,3801 \\
\hline & 1 & 1 & 0,0039 & 0,0070 & 0,0043 & 0,0039 & 0,0039 \\
\hline \multirow{14}{*}{ Latossolo Vermelho } & 1 & 2 & 0,0110 & 0,0196 & 0,0114 & 0,0109 & 0,0110 \\
\hline & 1 & 4 & 0,0258 & 0,0464 & 0,0269 & 0,0260 & 0,0261 \\
\hline & 1 & 8 & 0,0442 & 0,0790 & 0,0426 & 0,0443 & 0,0444 \\
\hline & 2 & 1 & 0,0086 & 0,0154 & 0,0095 & 0,0086 & 0,0086 \\
\hline & 2 & 2 & 0,0221 & 0,0398 & 0,0246 & 0,0223 & 0,0224 \\
\hline & 2 & 4 & 0,0422 & 0,0766 & 0,0502 & 0,0428 & 0,0431 \\
\hline & 2 & 8 & 0,0996 & 0,1806 & 0,0962 & 0,1016 & 0,1016 \\
\hline & 4 & 1 & 0,0177 & 0,0317 & 0,0219 & 0,0177 & 0,0178 \\
\hline & 4 & 2 & 0,0486 & 0,0891 & 0,0494 & 0,0501 & 0,0501 \\
\hline & 4 & 4 & 0,0660 & 0,1545 & 0,0995 & 0,0867 & 0,0869 \\
\hline & 4 & 8 & 0,2039 & 0,3678 & 0,1849 & 0,2073 & 0,2069 \\
\hline & 7 & 1 & 0,0274 & 0,0551 & 0,0360 & 0,0309 & 0,0310 \\
\hline & 7 & 2 & 0,0912 & 0,1684 & 0,0929 & 0,0948 & 0,0947 \\
\hline & 7 & 4 & 0,2065 & 0,3815 & 0,1890 & 0,2161 & 0,2146 \\
\hline \multirow{17}{*}{ Neossolo Flúvico } & 7 & 8 & 0,3386 & 0,6130 & 0,3210 & 0,3451 & 0,3448 \\
\hline & 1 & 1 & 0,0026 & 0,0048 & 0,0026 & 0,0027 & 0,0027 \\
\hline & 1 & 2 & 0,0054 & 0,0097 & 0,0053 & 0,0054 & 0,0055 \\
\hline & 1 & 4 & 0,0106 & 0,0201 & 0,0086 & 0,0112 & 0,0113 \\
\hline & 1 & 8 & - & - & - & - & - \\
\hline & 2 & 1 & 0,0043 & 0,0076 & 0,0040 & 0,0042 & 0,0043 \\
\hline & 2 & 2 & 0,0102 & 0,0181 & 0,0108 & 0,0100 & 0,0102 \\
\hline & 2 & 4 & 0,0186 & 0,0355 & 0,0182 & 0,0198 & 0,0200 \\
\hline & 2 & 8 & 0,0335 & 0,0621 & 0,0317 & 0,0346 & 0,0350 \\
\hline & 4 & 1 & 0,0100 & 0,0180 & 0,0106 & 0,0100 & 0,0101 \\
\hline & 4 & 2 & 0,0284 & 0,0531 & 0,0282 & 0,0295 & 0,0298 \\
\hline & 4 & 4 & 0,0765 & 0,1364 & 0,0802 & 0,0761 & 0,0767 \\
\hline & 4 & 8 & 0,0877 & 0,1583 & 0,0823 & 0,0883 & 0,0890 \\
\hline & 7 & 1 & 0,0194 & 0,0357 & 0,0187 & 0,0199 & 0,0201 \\
\hline & 7 & 2 & 0,0397 & 0,0740 & 0,0359 & 0,0412 & 0,0416 \\
\hline & 7 & 4 & 0,0902 & 0,1631 & 0,0866 & 0,0909 & 0,0918 \\
\hline & 7 & 8 & 0,1459 & 0,2764 & 0,1482 & 0,1538 & 0,1555 \\
\hline
\end{tabular}




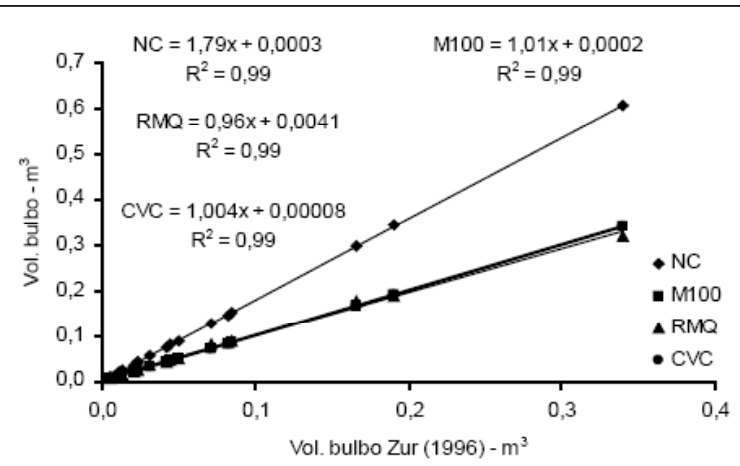

Luvissolo Crômico

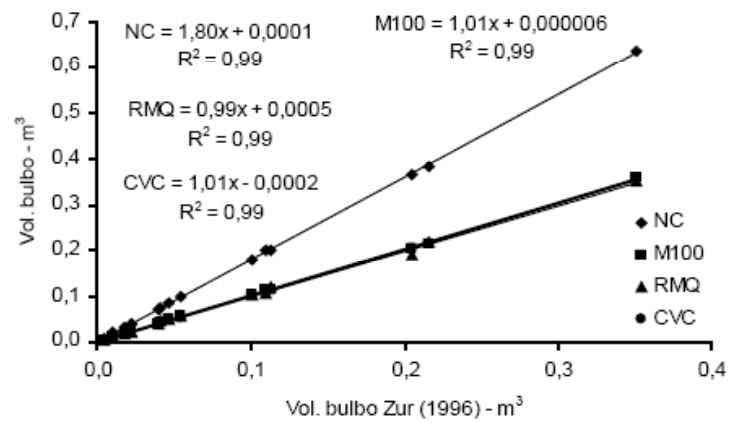

Cambissolo Háplico

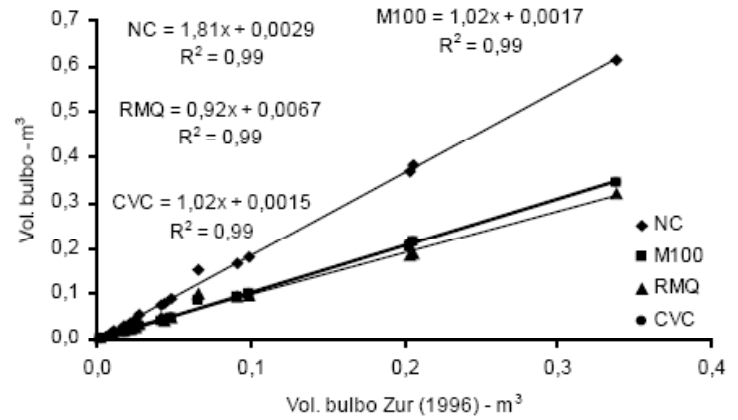

Latossolo Vermelho

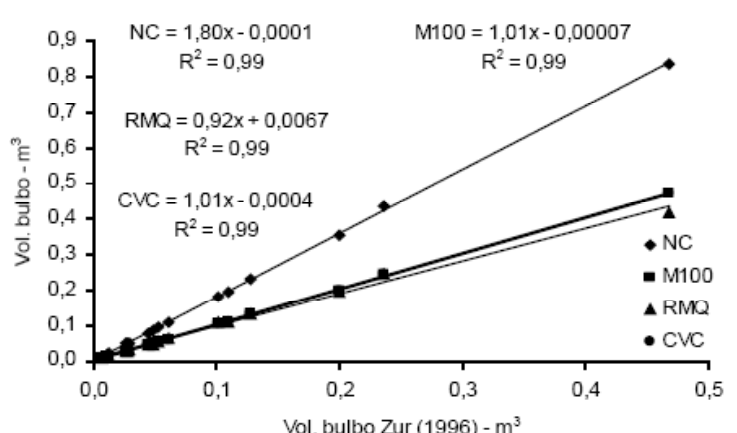

Argissolo Vermelho-Amarelo

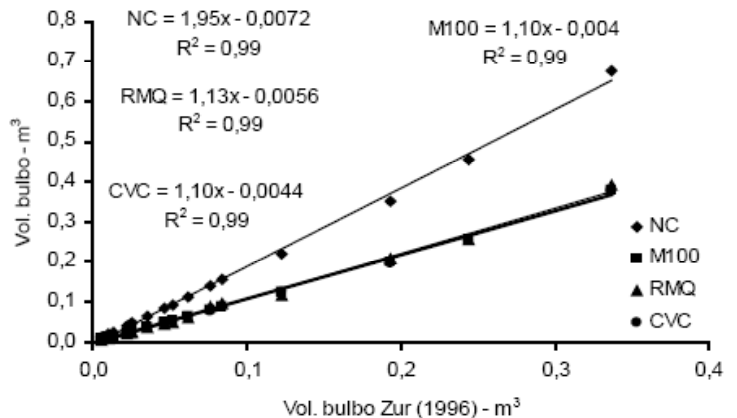

Neossolo Quartzarênico

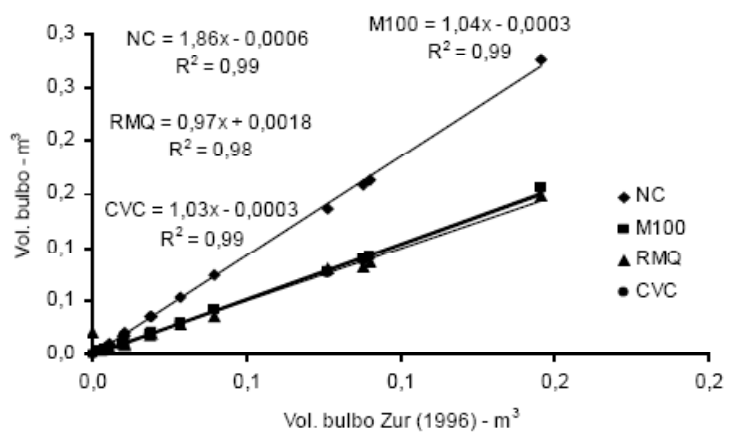

Neossolo Flúvico

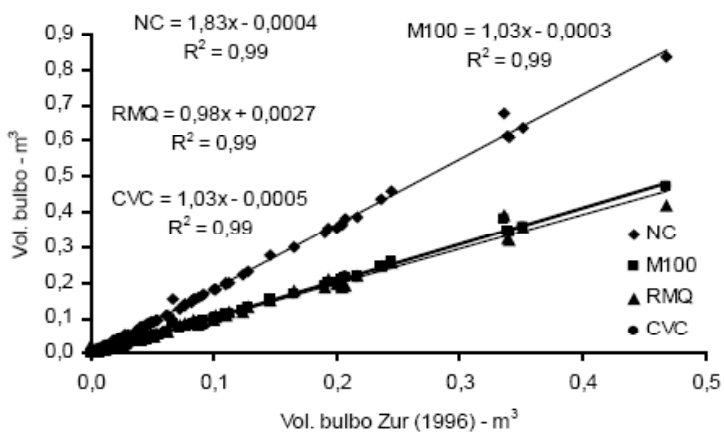

Todos os solos

Figura 1 - Volume do bulbo molhado estimado pelos modelos NARDA \& CHAWLA (2002) (NC), pela revolução do modelo quadrático (RMQ) e pela correção do volume do cilindro (CVC) e baseado no volume da esfera (M100), em função do estimado por ZUR (1996). 
Tabela 3 - Coeficientes para o modelo de superfície de resposta do volume do bulbo molhado $\left(\mathrm{m}^{3}\right)$ para os modelo de ZUR (1996) (NC), pela revolução do modelo quadrático (RMQ) e pela correção do volume do cilindro (CVC) e baseado no volume da esfera (M100), em função da vazão do emissor $\left(\mathrm{L} \mathrm{h}^{-1}\right)$ e do tempo de aplicação de água (h), $V=a \cdot t^{b} . q^{c}$, para os solos estudados.

\begin{tabular}{|c|c|c|c|c|}
\hline Solos & a & $\mathrm{b}$ & $\mathrm{c}$ & $\mathrm{R}^{2}$ \\
\hline \multicolumn{5}{|c|}{ ZUR (1996) } \\
\hline Luvissolo Crômico & 0,0045 & 1,1520 & 0,9985 & 0,9903 \\
\hline Argissolo Vermelho-Amarelo & 0,0050 & 1,2372 & 1,0211 & 0,9908 \\
\hline Cambissolo Háplico & 0,0072 & 1,0403 & 0,9136 & 0,9900 \\
\hline Neossolo Quartzarênico & 0,0072 & 1,0885 & 0,8541 & 0,9653 \\
\hline Latossolo Vermelho & 0,0056 & 1,0638 & 0,9976 & 0,9803 \\
\hline Neossolo Flúvico & 0,0038 & 1,0029 & 0,8335 & 0,9542 \\
\hline Todos os solos & 0,0056 & 1,0991 & 0,9439 & 0,8761 \\
\hline Luvissolo Crômico & 0,0058 & 1,0562 & 0,9452 & 0,9937 \\
\hline Argissolo Vermelho-Amarelo & 0,0067 & 1,1467 & 0,9136 & 0,9883 \\
\hline Cambissolo Háplico & 0,0071 & 1,0664 & 0,8927 & 0,9881 \\
\hline Neossolo Quartzarênico & 0,0060 & 1,1750 & 0,9277 & 0,9823 \\
\hline Latossolo Vermelho & 0,0068 & 1,0111 & 0,9136 & 0,9951 \\
\hline Neossolo Flúvico & 0,0034 & 1,0321 & 0,8510 & 0,9424 \\
\hline Todos os solos & 0,0060 & 1,0809 & 0,9130 & 0,8800 \\
\hline Luvissolo Crômico & 0,0046 & 1,1510 & 0,9968 & 0,9905 \\
\hline Argissolo Vermelho-Amarelo & 0,0050 & 1,2588 & 1,0059 & 0,9894 \\
\hline Cambissolo Háplico & 0,0070 & 1,0424 & 0,9276 & 0,9917 \\
\hline Neossolo Quartzarênico & 0,0061 & 1,1814 & 0,9000 & 0,9731 \\
\hline Latossolo Vermelho & 0,0062 & 1,0573 & 0,9595 & 0,9852 \\
\hline Neossolo Flúvico & 0,0036 & 1,0279 & 0,8500 & 0,9623 \\
\hline Todos os solos & 0,0055 & 1,1213 & 0,9472 & 0,8802 \\
\hline Luvissolo Crômico & 0,0046 & 1,1485 & 0,9957 & 0,9906 \\
\hline Argissolo Vermelho-Amarelo & 0,0051 & 1,2508 & 1,0049 & 0,9897 \\
\hline Cambissolo Háplico & 0,0072 & 1,0368 & 0,9240 & 0,9914 \\
\hline Neossolo Quartzarênico & 0,0062 & 1,1746 & 0,8981 & 0,9732 \\
\hline Latossolo Vermelho & 0,0062 & 1,0546 & 0,9606 & 0,9860 \\
\hline Neossolo Flúvico & 0,0037 & 1,0288 & 0,8505 & 0,9626 \\
\hline Todos os solos & 0,0055 & 1,1165 & 0,9459 & 0,8815 \\
\hline
\end{tabular}

da correção para o volume do cilindro (CVC) e do M100 estimaram satisfatoriamente o volume do bulbo molhado, destacando-se, na figura 1 , o ajuste feito para todos os solos. Assim, pode-se inferir que os modelos avaliados, com exceção do modelo proposto por NARDA \& CHAWLA (2002), estimam com bastante precisão o volume molhado.

Sendo o volume molhado do solo função da vazão do emissor e do tempo de aplicação de água, ajustou-se o volume molhado em função de $q$ e $t$ pelo modelo de superfície de resposta $V=a \cdot t^{b} \cdot q^{c}$ para os solos estudados (Tabela 3 ), onde se observa que este modelo pode ser utilizado para estimativa do volume molhado. O coeficiente de determinação para o ajuste feito em cada solo foi superior quando comparado para todos os solos, mesmo assim, considerando-se a variabilidade entre os solos, o ajuste para todos os solos foi bom, com $\mathrm{R}^{2}$ médio superior a $95 \%$.

Levando-se em consideração a média do volume molhado médio para as diferentes combinações de $q$ e $t$, observa-se, na tabela 4 , que o volume médio foi superior para o Argissolo, sendo seguido pelo Cambissolo e pelo Neossolo Quatzarênico, que apresentaram aproximadamente $87 \%$ do volume do Argissolo. Após estes, aparecem o Latossolo, o Luvissolo e o Neossolo Flúvico, com 81, 77 e 40\% do volume do Argissolo, respectivamente.

Pelo teste de identidade de modelo, utilizado para estimar o volume molhado do solo pela equação proposta por ZUR (1996) em função do volume de água 
Tabela 4 - Volume médio do bulbo molhado para as combinações da vazão do emissor $\left(q, \mathrm{~L} \mathrm{~h}^{-1}\right)$ e do tempo de aplicação de água $(t$, h) para os solos estudados para os modelos de ZUR (1996), NARDA \& CHAWLA (2002) (NC), pela revolução do modelo quadrático (RMQ) e pela correção do volume do cilindro (CVC) e baseado no volume da esfera (M100).

\begin{tabular}{|c|c|c|c|c|c|}
\hline Solo & ZUR & $\mathrm{N} \& \mathrm{C}$ & RMQ & $\mathrm{CVC}$ & M100 \\
\hline & \multicolumn{5}{|c|}{ 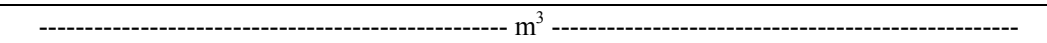 } \\
\hline Luvissolo Crômico & $0,0751(0,77)$ & $0,1347(0,77)$ & $0,0759(0,79)$ & $0,0755(0,77)$ & $0,0758(0,77)$ \\
\hline Argissolo Vermelho-Amarelo & $0,0976(1,00)$ & $0,1757(1,00)$ & $0,0959(1,00)$ & $0,0986(1,00)$ & $0,0988(1,00)$ \\
\hline Cambissolo Háplico & $0,0852(0,87)$ & $0,1537(0,87)$ & $0,0849(0,88)$ & $0,0859(0,87)$ & $0,0864(0,87)$ \\
\hline Neossolo Quartzarênico & $0,0846(0,87)$ & $0,1583(0,90)$ & $0,0900(0,94)$ & $0,0889(0,90)$ & $0,0890(0,90)$ \\
\hline Latossolo Vermelho & $0,0786(0,81)$ & $0,1453(0,83)$ & $0,0788(0,82)$ & $0,0818(0,83)$ & $0,0817(0,83)$ \\
\hline Neossolo Flúvico & $0,0389(0,40)$ & $0,0715(0,41)$ & $0,0381(0,40)$ & $0,0398(0,40)$ & $0,0402(0,41)$ \\
\hline
\end{tabular}

Valores entre parênteses referem-se à porcentagem do volume molhado em relação ao maior volume estimado.

aplicado ( $q \times \mathrm{x} t$, VAA), verificou-se que o volume molhado para o Luvissolo, o Cambissolo, o Neossolo Quartzarênico e o Latossolo pode ser estimado por uma só equação (VBM=-0,002228+0,006332**VAA, com $\left.\mathrm{R}^{2}=0,9734\right)$. Ao contrário desses solos, tanto para $\mathrm{o}$ Argissolo Vermelho-Amarelo (VBM=$\left.0,008850+0,008108^{* *} \mathrm{VAA}, \mathrm{com}^{2}=0,9812\right)$, como para o Neossolo Flúvico (VBM=0,002181+0,002724**VAA, com $\mathrm{R}^{2}=0,9433$ ), o volume molhado em função do volume de água aplicado deve ser estimado por equações diferentes.

\section{CONCLUSÃO}

Com exceção do modelo proposto por NARDA \& CHAWLA (2002), os demais modelos estimam satisfatoriamente o volume de solo molhado pela irrigação por gotejamento superficial. O volume médio molhado para as mesmas combinações de vazão do emissor $(q)$ e para o tempo de aplicação de água $(t)$ foi maior no Argissolo e menor no Neossolo Flúvico. Com exceção do Argissolo e do Neossolo Flúvico, o volume molhado do solo pode ser estimado por uma única equação matemática.

\section{REFERÊNCIAS}

BARRETO, C.V.G. et al. Técnica de avaliação de bulbo úmido por múltiplos cortes em trincheira. Irriga, v.13, n.2, p.160169, 2008.

BRESLER, E. Analysis of trickle irrigation with application to design problems. Irrigation Science, v.1, p.3-17, 1978.

CARMO FILHO, F. et al. Dados meteorológicos de Mossoró (Jan. de 1988 à Dez. de 1990). Mossoró: ESAM/FGD, 1991. 121p. (Coleção Mossoroense).

EMBRAPA. Centro Nacional de Pesquisas de Solos. Sistema brasileiro de classificação de solos. Rio de Janeiro, 2006. $306 \mathrm{p}$.
FARNESELLI, M. et al. Depth and width of the wetted zone in a sandy soil after leaching drip-irrigation events and implications for nitrate-load calculation. Communications in Soil Science and Plant Analysis, v.39, p.1183-1192, 2008

HAO, A. et al. Estimation of wet bulb formation in various soil during drip irrigation. Journal of the Faculty of Agriculture, Kyushu University, v.52, n.1, p.187-193, 2007.

LUBANA, P.P.S.; NARDA, N.K. Soil water dynamics model for trickle irrigated tomatoes. Agricultural Water Management, v.37, p.145-161, 1998. Disponível em: <http:// www.sciencedirect.com/science? ob=MImg\& imagekey $=$ B6T3X3 V G M 9SB - $5-1$ H\&_cdi $=4958 \&$ \& s er $=684796 \&$

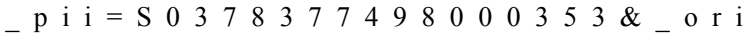
g i n $=$ b rowse \&_zon e $=$ rs 1 t c o ve r D a t e $=07 \% 2 \mathrm{~F} 01 \% 2 \mathrm{z} \mathrm{S} \mathrm{k} \mathrm{z} \mathrm{V} \mathrm{\&} \mathrm{m}$ $\overline{\mathrm{d}} 5=\mathrm{a} 566 \mathrm{f} 9 \mathrm{f} 3 \mathrm{ae} 092 \mathrm{~d} 6229045 \mathrm{e} 89 \mathrm{feccd} 78 \mathrm{~d} \& \mathrm{ie}=/$ sdarticle.pdf $>$. Acesso em: 22/09/2002.

MAIA, C.E. et al. Dimensões de bulbo molhado na irrigação por gotejamento superficial. Revista Ciência Agronômica, n.41, v.1, p.141-158, 2010. Disponível em: <http:// www.ccarevista.ufc.br/seer/index.php/ccarevista/article/view/ 531/419>. Acesso em: 21 set. 2010.

NARDA, N.K., CHAWLA, J.K. A simple nitrate submodel for trickle fertigated potatoes. Irrigation \& Drainage, v.51. p.361-371, 2002.

PROVENZANO, G. Using HYDRUS-2D simulation model to evaluate wetted soil volume in subsurface drip irrigation systems. Journal of Irrigation and Drainage Engineering, v.133, n.4, p.342-349, 2007.

REGAZZI, A.J. Teste para verificar a identidade de modelos de regressão e a igualdade de alguns parâmetros no caso de dados de delineamentos experimentais. Revista Ceres, v.46, n.266, p.383-409, 1999.

SANTOS, B.M. et al. Length of irrigation and soil humidity as basis for delivering fumigants through drip lines in Florida spodosols. Proceedings Florida State Horticultural Society, v.116, p.85-87, 2003.

SIMONNE, E.H.D.W. et al. Understanding water movement in mulched bed on sandy soils: an approach to ecologically 
sound fertigation in vegetable production. Acta Horticultural, v.700, p.173-178, 2005.

SINGH, D.K. et al. Simulation of soil wetting pattern with subsurface drip irrigation from line source. Agricultural Water Management, v.83, p.130-134, 2006. Disponível em: <http:// www.sciencedirect.com/science?_ob=MImg\&_imagekey=B6T3X4 HWXP10-1-9\&_cdi $=4958 \&$ user $=684796 \&$ pii $=$ S 0 $378377405003586 \&$ \& origin=browse\&_zone $=$ rslt_list_item\&_coverDate $=05 \% 2 \mathrm{~F} 16 \% 2 \mathrm{~F} 2006 \&$ _ $\mathrm{s} \mathrm{k}=999169998 \& \mathrm{w} \mathrm{ch} \mathrm{p}=\mathrm{d} \mathrm{G} \mathrm{L} \mathrm{b} \mathrm{V} \mathrm{z} \mathrm{b} \mathrm{-}$
zSkzS\&md5=e342f74bfb $21 \mathrm{f} 8 \mathrm{de} 93 \mathrm{~b} 0 \mathrm{bec} 26 \mathrm{ed} 213 \mathrm{f} 4 \& \mathrm{ie}=/$ sdarticle.pdf $>$. Acesso em: 20/10/2008. doi:10.1016/ j.agwat.2005.11.002.

THABET, M.; ZAYANI, K. Wetting patterns under trickle source in a loamy sand soil of south Tunisia. AmericanEurasian Journal of Agricultural \& Environmental Sciences, v.03, n.01, p.38-42, 2008.

ZUR, B. Wetted soil volume as a design objective in trickle irrigation. Irrigation Science, v.16, p.101-105, 1996. 